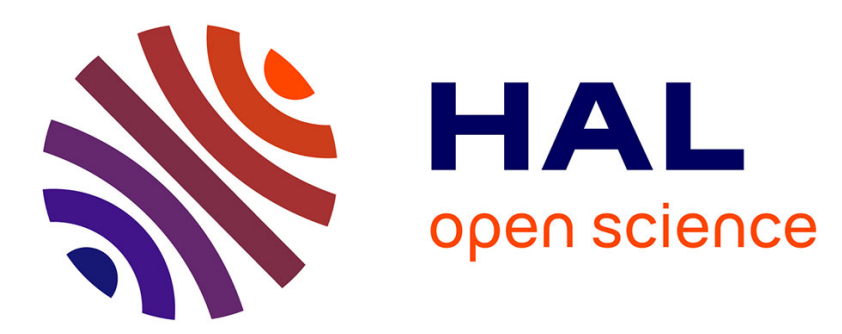

\title{
AN IMPACT IONIZATION MODEL FOR CURRENT CONTROLLED NEGATIVE RESISTANCE AND g-r INDUCED NONEQUILIBRIUM PHASE TRANSITIONS
}

\author{
E. Schöll
}

\section{To cite this version:}

E. Schöll. AN IMPACT IONIZATION MODEL FOR CURRENT CONTROLLED NEGATIVE RESISTANCE AND g-r INDUCED NONEQUILIBRIUM PHASE TRANSITIONS. Journal de Physique Colloques, 1981, 42 (C7), pp.C7-57-C7-62. 10.1051/jphyscol:1981706 . jpa-00221642

\section{HAL Id: jpa-00221642 https://hal.science/jpa-00221642}

Submitted on 1 Jan 1981

HAL is a multi-disciplinary open access archive for the deposit and dissemination of scientific research documents, whether they are published or not. The documents may come from teaching and research institutions in France or abroad, or from public or private research centers.
L'archive ouverte pluridisciplinaire HAL, est destinée au dépôt et à la diffusion de documents scientifiques de niveau recherche, publiés ou non, émanant des établissements d'enseignement et de recherche français ou étrangers, des laboratoires publics ou privés. 


\section{AN IMPACT IONIZATION MODEL FOR CURRENT CONTROLLED NEGATIVE RESISTANCE AND $g-r$ INDUCED NONEQUILIBRIUM PHASE TRANSITIONS}

E. Schö11

Institut f. Theoret. Physik B, RWTH Aachen, D-51 Aachen, FRG

Résumé. - Nous présentons dans ce papier un modèle simple de génération-recombination basé sur un mécanisme d'ionisation des donneurs par impacts à deux étapes. Ce modèle conduit à une caractéristique courantTension de type $S$ et à des transitions de phases hors d'equilibre entre les branches hautes et basses de la résistivité. Nous avons montré qu' une règle de "surfaces égales" est une condition nécessaire pour la formation de filaments ou de couches de courant.

Abstract. - A simple generation-recombination ( $g-r$ ) model based upon a two-step impact ionization mechanism of donors is presented. It leads to an s-type current-voltage characteristic and to nonequilibrium phase transitions between its high and low resistivity branches. The homogeneous steady state corresponding to the falling branch is shown to be unstable against the formation of high and low current layers and filaments, and an equal area rule for their coexistence is established.

\section{Introduction}

Current controlled negative differential resistance associated with an S-type current-voltage characteristic and with threshold switching is a wide-spread phenomenon in amorphous ${ }^{11}$ and crystalline ${ }^{2)}$ semiconductors, and insulators ${ }^{3)}$ for which thermal as well as electronic mechanisms have been proposed. Here we consider a generation-recombination $(g-r)$ model which is based upon the impact ionization of both ground state and excited donors by hot electrons. It involves an $n$-type semiconductor with $N_{D}$ donors, partially compensated by $N_{A}<N_{D}$ fully occupied acceptors, at low temperature. Other $\mathrm{g}-\mathrm{r}$ models with impact ionization of deeply trapped electrons and holes were studied previous$1 y^{4)}$.

\section{The model}

The g-r processes considered are shown schematically in Fig. 1. 


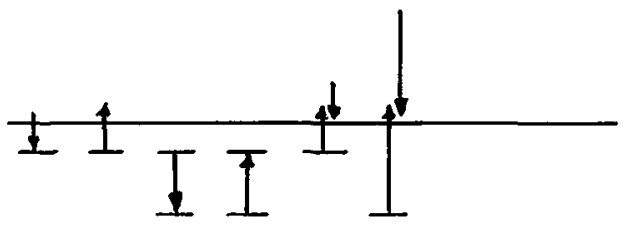

conduction band

$\mathrm{T}_{1}^{\mathrm{S}} \mathrm{X}_{1}^{\mathrm{S}} \mathrm{T}^{*} \mathrm{X}^{*} \mathrm{X}_{1}^{*} \mathrm{X}_{1}$ rate constants

Fig. 1: Schematic g-r processes involved in the model.

The rate constants depend upon the electric field $E$. It is assumed that in the regime of negative differential resistance the field dependence of the impact ionization coefficients dominates that of all other rate constants and of the mobility.

The transport equations are the following:

$$
\begin{aligned}
\underline{j} & =n e \mu \underline{E}+e D \underline{\nabla n} \\
\dot{n}-\frac{1}{e} \underline{\nabla} \cdot \underline{j} & =f\left(n, n_{D^{\prime}} n_{D^{*}}\right) \\
\dot{n}_{D} & =g\left(n, n_{D^{\prime}}, n_{D^{*}}\right) \\
\dot{n}_{D^{*}} & =-f\left(n, n_{D^{\prime}} n_{D^{*}}\right)-g\left(n, n_{D^{\prime}}, n_{D^{*}}\right) \\
\underline{\nabla} \cdot \underline{E} & =\frac{4 \pi e}{\varepsilon}\left(N_{D^{-}}-N_{A}-n-n_{D}-n_{D^{*}}\right), \quad \underline{\nabla} \times \underline{E}=0
\end{aligned}
$$

The $g-r$ rates are given by

$f\left(n, n_{D^{\prime}} n_{D^{*}}\right)=x_{1}^{S} n_{D^{*}}-T_{1}^{S} p_{D} n+x_{1} n_{D} n+x_{1}^{*} n_{D^{*}} n$

$g\left(n, n_{D^{\prime}} n_{D^{*}}\right)=-x^{*} n_{D}+T^{*} n_{D^{*}}-x_{1} n_{D} n$

$\mathrm{n}$ concentration of free electrons

$n_{D} \quad$ concentration of electrons in donor ground states

$n_{D^{*}}$ concentration of electrons in donor excited states

$\mathrm{p}_{\mathrm{D}}=\mathrm{N}_{\mathrm{D}}-\mathrm{n}_{\mathrm{D}}-\mathrm{n}_{\mathrm{D}^{*}}$ concentration of unoccupied donors

$\mathrm{N}_{\mathrm{D}} \quad$ total donor concentration

$N_{A}<N_{D}$ compensating acceptor concentration

j electron current density

$\mu$ electron mobility

D diffusion constant

Table I: List of symbols 


\section{Homogeneous steady states}

The homogeneous solutions of $(1)-(5)$ are determined by

$$
\dot{n}=f\left(n, n_{D}\right) \quad, \dot{n}_{D}=g\left(n, n_{D}\right)
$$

and $n_{D} *=N_{D}-N_{A}-n-n_{D}$ (local neutrality).

Depending upon the values of the rate constants, (8) admits up to three steady states, two of which are stable against small fluctuations

$\delta_{n}, \delta_{n}$, while the third is not. The two stable steady states $\left(\mathrm{n}_{1}<\mathrm{n}_{3}\right)$ correspond to high $\left(\mathrm{n}_{1}\right)$ and low $\left(\mathrm{n}_{3}\right)$ resistivity states. The carrier concentrations depend upon the applied static electric field $E_{0}=V / L$ Via $X_{1}$ and $x_{1}^{*}$, where $V$ is the sample voltage, and $L$ the sample length. Thus $j=n\left(\mathrm{E}_{0}\right) e^{\mu} \mathrm{E}_{0}$ yields an s-type static currentvoltage characteristic, which is plotted in Fig. 2 for the particular field dependence $\mathrm{x}_{1}=5 \times 10^{-8} \exp \left(-6 / \mathrm{E}_{0}\right) \mathrm{cm}^{3} \mathrm{~s}^{-1}, \mathrm{x}_{1}^{*}=10^{-6} \exp \left(-1.5 / \mathrm{E}_{\mathrm{o}}\right)$ $\mathrm{cm}^{3} \mathrm{~s}^{-1}$.

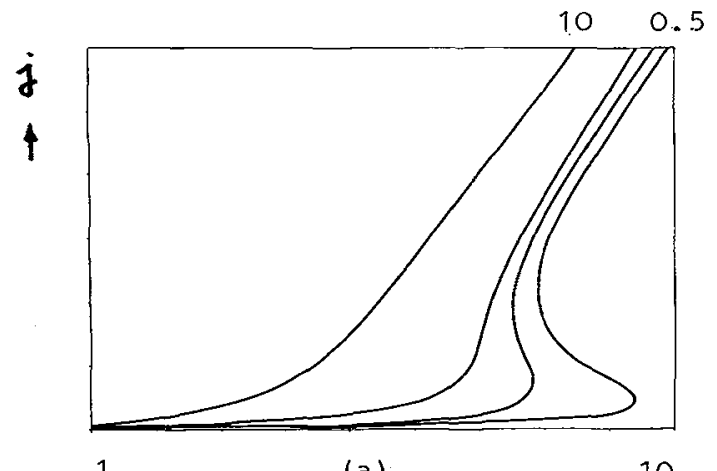

(a)
10

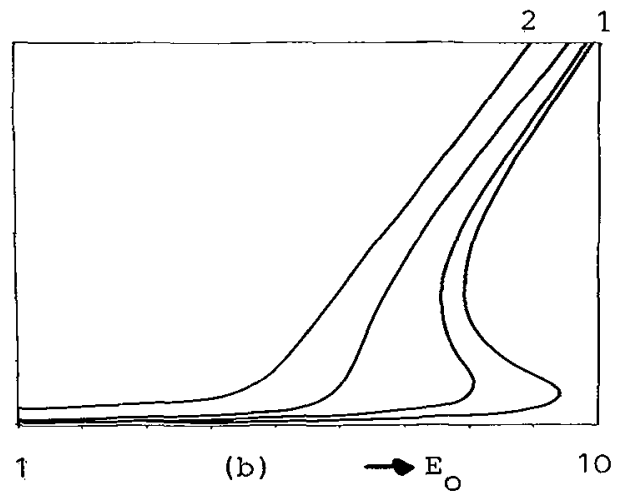

Fig. 2: Current-voltage characteristics for $\mathrm{N}_{\mathrm{D}}=1.5 \times 1015 \mathrm{~cm}^{-3}$, $\mathrm{N}_{\mathrm{A}} / \mathrm{N}_{\mathrm{D}}=1 / 3, \mathrm{~T}_{1}^{\mathrm{S}}=10^{-6} \mathrm{~cm}^{3} \mathrm{~s}^{-1}, \mathrm{~T}^{*}=10^{6} \mathrm{~s}^{-1}$. The other parameters are in $\boldsymbol{\mu s}^{-1}$ : (a) $x_{1}^{S}=0.5,1,2,10 ; x^{*}=1 ;$ (b) $x^{*}=1,1.1,1.5,2 ; x_{1}^{S}=0.5$.

Switching between the high and the low resistivity branches of the current-voltage characteristic can be regarded as a nonequilibrium phase transition of first order between two steady states with overlapping stability range, brought about by variation of $\mathrm{E}_{\circ}$ taken as a control parameter. More generally, $E_{O}$ is determined from the load line of the external circuit with impedance $R$ and applied voltage $U_{0}$. This includes in particular voltage controlled $(R \rightarrow 0)$ and current controlled $(R \rightarrow \infty)$ conditions.

By appropriate irradiation the ionisation coefficient $x_{1}^{S}$ can be increased, leading to smaller and eventually vanishing bistability 
ranges (Fig. 2a). Similarly, with increasing $x^{*}$ (e.g. increasing temperature, Fig. 2b) or decreasing compensation ratio $N_{A} / N_{D}$ the bistability vanishes. This agrees well with the qualitative behaviour known from experiments ${ }^{5}$.

\section{Inhomogeneous steady states}

For small deviations $\delta_{\phi}:=\left(\delta_{\underline{E}}, \delta_{\mathrm{n}}, \delta_{\mathrm{n}_{D}}, \delta_{\mathrm{n}_{D^{*}}}\right)$ from the unstable homogeneous steady state $\left(E_{0}, n, n_{D^{\prime}} n_{D^{*}}\right)(1)-(5)$ can be linearized. With the ansatz $\delta \phi \sim \exp i(\underline{k} . \underline{x}-\omega t)$ for periodic boundary conditions and fixed current we find the dispersion law

$O=(i \omega-\Gamma)\left[(i \omega-\Gamma)\left(i \omega+\lambda_{1}\right)\left(i \omega+\lambda_{2}\right)+\left(i \mu E_{0} \cdot \underline{k}-D k^{2}\right)\left(-\omega^{2}-i \omega \theta+\Delta\right)\right]$

where $\Gamma:=\frac{4 \pi \text { en } \mu}{\varepsilon}$ is the dielectric relaxation frequency,

$\boldsymbol{\lambda}_{\boldsymbol{1}}>0>\boldsymbol{\lambda}_{2}$ are the eigenvalues of the linearized rate equations (8), and $\theta, \Delta$ are positive constants depending upon the rate coefficients, and hence upon $E_{0}$. The spectrum given by (10) contains the damped dielectric relaxation mode $\boldsymbol{\omega}=-i \Gamma$ and three coupled relaxation - recombination - diffusion modes. For transverse perturbations $\left(\underline{\mathrm{k}}, \delta \underline{\mathrm{E}} \perp \underline{\mathrm{E}}_{\mathrm{O}}\right)$ we obtain in the long wavelength limit an undamped recombination-diffusion mode

$$
\omega=i\left(\lambda_{1}-\tilde{D} k^{2}\right)
$$

with a dressed diffusion constant

$$
\tilde{D}=\mathrm{D} \frac{\boldsymbol{\lambda}_{1}^{2}+\boldsymbol{\lambda}_{1} \theta+\Delta}{\left(\boldsymbol{\lambda}_{1}+\Gamma\right)\left(\boldsymbol{\lambda}_{1}-\boldsymbol{\lambda}_{2}\right)}
$$

This leads to the bifurcation of a family of inhomogeneous stationary solutions.

To investigate the full nonlinear equations (1)-(5) for a plane geometry, we assume that the concentrations and the field $\underline{E}=E_{0} \underline{e}_{z}+E_{\perp} \underline{e}_{x}$ depend upon the coordinate $x$ transverse to the static field $E_{0}$ only, and that the transverse current vanishes. In the steady state $(1)-(5)$ can then be reduced to

$$
\frac{\mathrm{d}}{\mathrm{d}} \mathrm{n}^{\mathrm{n}}=-\mathrm{n} \varepsilon \quad \frac{\mathrm{d}}{\mathrm{d}} \boldsymbol{\xi}=\rho(\mathrm{n})
$$

with the dimensionless coordinate $\xi=\mathrm{x} / \mathrm{L}_{D}$ and transverse field $\varepsilon=\left(e L_{D} E_{\perp}\right) /(k T)$, where $L_{D}:=\left[(\varepsilon D) /\left(4 \pi e \mu\left(N_{D}-N_{A}\right)\right]^{1 / 2}\right.$. The charge density $\rho(n)$ is found from (3)-(5) by eliminating $n^{\prime}{ }^{\prime} n_{D^{*}}$ and is a nonlinear function of $n$. It depends upon $\mathrm{E}_{\mathrm{o}} \mathrm{via} \mathrm{x}_{1}, \mathrm{x}_{1}^{*}$, and we assume $E_{\perp} \ll E_{O}$. A first integral of (13) is 


$$
\varepsilon(n)= \pm \sqrt{-2 \phi(n)+\text { const. }}
$$

with $\phi(n):=\int(\rho(n) / n) d n$.

Eq. (14) includes inhomogeneous oscillatory, solitary and run-away solutions (Fig. 3). The homogeneous steady states $\left(n_{1}, n_{2}, n_{3}\right)$ are the extremal points of $\phi(n)$. A solitary solution corresponding to the coexistence of $n_{1}$ and $n_{3}$, i.e. to plane low and high current layers, exists if and only if the condition

$$
\int_{n_{1}}^{n_{3}} \rho(n) \frac{d n}{n}=0
$$

is satisfied. This is analogous to the Maxwell construction obtained for equilibrium and chemical nonequilibrium phase transitions ${ }^{6)}$ or the equal area rule known from the Gunn effect ${ }^{7)}$ and from other switching models ${ }^{1)}$.

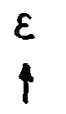

0

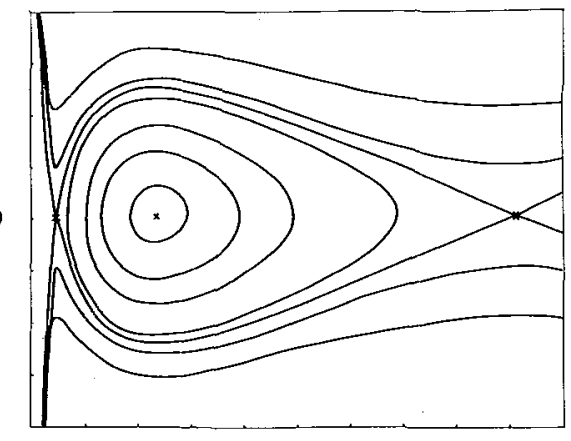

Fig.3: Phase portrait of the inhomogeneous steady states given by (14) with (15). The parameter varying along the phase trajectories is the transverse coordinate 3 . The saddle-to-saddle separatrices represent the solitary solutions. The numerical parameter: are those of Fig. 2(a), with $\mathrm{X}_{1}^{S}=0.5 \mu \mathrm{s}, \mathrm{E}_{\mathrm{o}}=8.5 \mathrm{~V} / \mathrm{cm}$.

For a cylindrical geometry (13) is replaced by

$$
\frac{d}{d r} n=-n \varepsilon \quad \frac{d}{d r} \varepsilon=-\frac{\varepsilon}{r}+\rho(n)
$$

where $r$ is the dimensionless radial coordinate. The equal area rule (15) has to be modified by a surface term

$$
\int_{n_{1}}^{n_{3}} \rho(n) \frac{d n}{n} \pm \frac{1}{r_{0}} \int_{n_{1}}^{n_{3}}\left(\frac{d}{d r} n\right) \frac{d n}{n^{2}}=0
$$

and leads to cylindrical high or low current filaments with mean radius $r_{0}$.

\section{Conclusion}

The mechanism leading to bistability in the above model can be interpreted as a coupled two-step impact ionization process:

The donor ground levels are depleted by impact ionization $\left(\mathrm{x}_{1}\right)$, which results in an enhancement of the excited donor population $n_{D^{*}}$, by (7). 
Simultaneously, the excited donors are impact ionized, with a rate

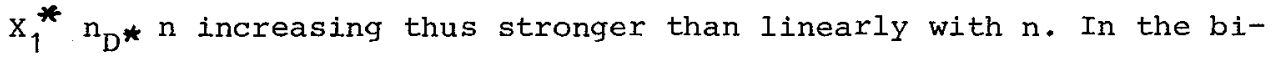
stability regime the impact ionization rate is negligible at lown, i.e. in the high resistivity state, where recombination is balanced by the simple generation process $x_{1}^{S}$. Due to the superlinear increase in the impact ionization rate, a second stable steady state is possible at large $\mathrm{n}$, i.e. the low resistivity state.

The model is applicable for materials where the dominant $g-r$ processes are those of Fig. 1. More so-phisticated g-r models, e.g. including Auger recombination, yield the same qualitative behaviour for suitable ranges of the rate constants.

There is a close analogy of the above switching transition with phase transitions in equilibrium and in other nonequilibrium systems ${ }^{8)}$. such as critical slowing down, soft mode instability of the homogeneous steady state against long wavelength perturbations, bifurcation of inhomogeneous solutions, and phase coexistence when certain equal area rules are satisfied.

\section{References}

(1) Adler D., Shur M.S., Silver M., Ovshinsky S.R., J. Appl. Phys. 51, $3289(1980)$.

(2) Bonch-Bruevich V.I., Zvyagin I.P., Mironov A.G., Domain Electrical Instabilities in Semiconductors. Consultant Bureau (New York) 1975.

(3) Klein N., Thin Solid Films $\underline{50}, 223$ (1978).

(4) Landsberg P.T., Pimpale A., J. Phys. C9, 1243 (1976).

Landsberg P.T., Robbins D.J., Schöll E., Phys. stat. sol. (a) $\underline{50}$, 423 (1978).

Robbins D.J., Landsberg P.T., Schöll E., Phys. stat. sol. (a) 65, $353(1981)$.

Schöll E., Landsberg P.T., Proc. Roy. Soc. A 365, 495 (1979).

(5) Khosla R.P., Fischer J.R., Burkey B.C., Phys. Rev. B , 2551 $(1973)$.

(6) Schlögl F., z. Phys. 253, 147 (1972).

(7) Shaw M.P., Grubin H.L., Solomon P., The Gunn-Hilsum Effect. Academic Press (New York) 1979.

(8) Büttiker M., Thomas H., Z. Physik B 33, 275 (1979), B 34, 301, (1979) .

Haken H., Synergetics. Springer (Berlin) 1977. 